\title{
O corpo na velhice e suas relações com as quedas a partir da narrativa de idosos
}

\author{
The body in old age and its relationships with falls \\ from the narrative of elderlies
}

Ana Thereza da Costa Estrêla (https://orcid.org/0000-0002-6142-9025) ${ }^{1}$

Rosana Machin (https://orcid.org/0000-0003-1306-4276) ${ }^{1}$

${ }^{1}$ Departamento de Medicina Preventiva, Faculdade de Medicina, Universidade de São Paulo. Av. Dr. Arnaldo 455, Cerqueira César. 01246-903 Pacaembu SP Brasil.

thereza.estrela1@gmail.com

\begin{abstract}
The purpose of this research was to investigate the body in old age and its relationships with falls. It was based on the assumption that the body is a historical, social and cultural construction, and that the idea of old age has been replaced by the idea of third age. Falls are considered a complex event with serious consequences for the elderly. The objective of the study was to investigate the experience of the body at old age and its relationships with falls. Using a qualitative method, semi-structured interviews were conducted with 15 individuals, 68 to 75 years old, with or without history of falls, who attended a geriatric outpatient clinic at a hospital autarchy in the city of São Paulo, from September 2017 to June 2018. The interviews were transcribed and an analysis of their content was made. The results showed a body which is experienced as the expression of an essence that is desired and is projected as a young one and falling becomes a reflection of old age and the exposure of a failure. The body experience does not seem to interfere directly with the risk of falls. However, its comprehension, as well as the representation of falls in old age, provides support to a preventive approach to this event.
\end{abstract}

Key words Human body, Body image, Ageing, Accidental falls, Health of the elderly
Resumo Esta pesquisa teve como enfoque investigar o corpo na velhice e suas relações com a queda. Partiu-se do pressuposto do corpo como uma construção histórica, social e cultural e da velhice substituída pela ideia da terceira idade. A queda é considerada um evento complexo com consequências graves para a pessoa idosa. O objetivo do estudo foi investigar a vivência do corpo na velhice e sua relação com as quedas. A pesquisa de natureza qualitativa realizou entrevistas semiestruturadas com 14 individuos entre 68 e 75 anos com ou sem história de quedas e que frequentavam um ambulatório de geriatria de uma autarquia hospitalar na cidade de São Paulo, entre setembro de 2017 e junho de 2018. As entrevistas foram transcritas e foi feita análise de conteúdo do material. Os resultados indicaram que o corpo é vivido como expressão de uma essência que se deseja e se projeta como jovem e cair torna-se um reflexo da velhice e a exposição de uma falha. A vivência de corpo não parece interferir diretamente sobre o risco para a queda, no entanto, sua compreensão, bem como a representação da queda na velhice, fornecem subsídios para uma abordagem preventiva em relação a esse evento.

Palavras-chave Corpo humano, Imagem corporal, Envelhecimento, Acidentes por quedas, Saúde do Idoso 


\section{Introdução}

A queda pode ocorrer em qualquer fase da vida. As causas que levam a esse evento podem ser tão variadas quanto as idades em que ele ocorre. $\mathrm{E}$ suas consequências podem ser as mais diversas tanto em função de sua magnitude, como em função da idade em que acontece.

A queda é definida como "vir a, inadvertidamente, ficar no solo ou em outro nível inferior, excluindo mudanças de posição intencionais para se apoiar em móveis, paredes ou outros objetos"'. É tida como um grave problema de saúde pública, que afeta, sobretudo, as pessoas maiores de $60 \operatorname{anos}^{2}$. As repercussões de uma queda se estendem desde o âmbito do indivíduo até os aspectos sociais ${ }^{3}$.

Cerca de um terço das pessoas com mais de 65 anos caem ao menos 1 vez por ano e metade delas cai ao menos 2 vezes por ano ${ }^{4}$. No âmbito do indivíduo idoso, uma queda significa desde fraturas e risco de morte, até medo de cair, restrição de atividades, declínio na saúde e aumento do risco de institucionalização. Nos aspectos sociais, ela pode onerar o serviço de saúde pelas consequências que a acompanham, tais como a necessidade de internações prolongadas e as mudanças das configurações familiares pela necessidade da disponibilização de algum familiar para os cuidados com o idoso caidor ${ }^{3}$.

Mesmo que não leve à morte, a lesão por queda contribui para o declínio funcional do indivíduo idoso e para a diminuição de sua capacidade de autocuidado. A efetividade da avaliação e intervenção para a redução do risco de quedas já é comprovada. Entretanto, não é uma abordagem simples, pois requer escolhas que envolvem desde as condições clínicas do paciente até o conflito entre seu desejo de independência e sua seguran$\mathrm{ça}^{5}$.

A queda pode estar associada a fatores de risco que podem ser divididos em intrínsecos e extrínsecos. Os intrínsecos se relacionam a alterações fisiológicas próprias do envelhecimento, comorbidades e uso de medicamentos. Já os extrínsecos estão ligados às circunstâncias sociais e ambientais em que se encontram os indivíduos ${ }^{6}$. Os fatores de risco individuais que se relacionam com o aumento do risco de quedas são: quedas prévias, disfunções do equilíbrio, fraqueza muscular, limitações visuais, uso de quatro ou mais medicações e de medicações psicotrópicas, dificuldade para andar, depressão, tontura, hipotensão ortostática, incapacidade em atividades básicas de vida diária, idade avançada, sexo feminino, comprometimento cognitivo, incontinência urinária e riscos ambientais ${ }^{4}$.

Embora muito se fale sobre as consequências físicas e os impactos sociais, sobretudo no sistema de saúde, a queda também envolve aspectos emocionais como o constrangimento com o evento e a ansiedade pelo risco de cair novamente ${ }^{7}$. Assim, a queda mostra-se um evento complexo com componentes fisiológicos, psíquicos e sociais e exige uma abordagem que leve em consideração esses fatores ${ }^{8}$.

Em um mundo desigual política, econômica e socialmente, o envelhecimento mostra-se variável, levando a uma velhice igualmente heterogênea, vivida de maneira diversa' ${ }^{9}$. Apesar das projeções demográficas acentuarem as dimensões sobre o envelhecimento, o contexto contemporâneo tem trazido um embaçamento das fronteiras etárias e a constituição da juventude como um bem a ser adquirido ${ }^{10}$. Isso tem tornado o envelhecimento um processo que não se define apenas pela idade cronológica.

Embora se reconheça o intenso processo de mudança em relação ao curso da vida ser tomado pela sua descronologização ${ }^{11}$, ou seja, a diminuição da relação entre as grades de idade e a carreira, as idades ainda são uma dimensão fundamental na organização social e no status de uma pessoa. No que concerne à velhice, as mudanças não são necessariamente tolerantes com a idade e no processo pós-moderno a juventude é um bem que reforça a promoção desse status.

Os saberes da medicina sobre o corpo envelhecido ${ }^{12}$, centrado nos processos de degeneração de tecidos e células, levam ao reconhecimento da velhice como um estado fisiológico. Uma metáfora médica que associa a velhice à doença ${ }^{13}$ perpassa o imaginário social de forma a caracterizar não só o envelhecimento físico, como também a experiência de envelhecer. Dessa forma, esses sujeitos passam a caracterizar a si mesmos e a sua experiência através de um discurso médico.

A institucionalização das aposentadorias como resposta a uma massa de trabalhadores, que estava envelhecendo permitiu uma associação entre velhice e invalide $z^{14}$ especialmente, pela centralidade da categoria trabalho na sociedade. Mas, trouxe como consequência o surgimento dos agentes gestores da velhice. A responsabilidade por esses velhos passa da família para esses gestores, consolidando, finalmente, a velhice como categoria etária ${ }^{12}$.

A partir da década de 1960, as caixas de aposentadoria se tornam agências financeiramente poderosas. Oferecendo um atendimento mais 
especializado em substituição a assistência, essas agências ajudam a diminuir a associação entre indigência e velhice e facilitam o surgimento da ideia de terceira idade ${ }^{14}$. O crescimento desse mercado vem acompanhado de uma nova linguagem em que a terceira idade substitui a velhi$\mathrm{ce}^{15}$. É nesse corpo na velhice, redesenhado pela terceira idade, que ocorre a queda.

O corpo na velhice e as possíveis relações que essa vivência tem com as quedas é a experiência vivida pelos próprios velhos e eles são os narradores privilegiados que, ao trazerem as informações reveladoras de si mesmos, revelam também o mundo em que vivem. $\mathrm{Na}$ interface entre as produções científicas, a vivência dentro de um grupo social, a relação com o mundo e com os outros sujeitos em que valores, simbolismos e conceitos se renovam ou permanecem, os velhos vivem esta etapa da vida imersos nos conteúdos culturais e sociais que os influenciam, mas que também são influenciados por eles. Em uma permanente troca entre representações que constroem e são construídas pelo grupo social, os velhos pesquisados vivem seu corpo de velho e estabelecem uma relação com as quedas, que pode influenciar seus cuidados ou a ausência deles.

Partindo desse quadro, o presente artigo aborda o corpo na velhice e suas relações com as quedas, considerando que corpo e velhice são construídos pelo contexto socio-histórico e as quedas são um grave problema de saúde pública. Nosso objetivo é compreender como o velho vivencia seu corpo e a relação que essa vivência tem com as quedas.

\section{Metodologia}

A abordagem metodológica da pesquisa é de caráter qualitativo. Entende-se que este método permite a compreensão do fenômeno a partir dos sujeitos que o vivenciam e das regras sociais e culturais que permeiam determinado tempo histórico ${ }^{16}$.

A técnica escolhida foi a entrevista semiestruturada, que abordava três eixos principais. $\mathrm{O}$ primeiro eixo tratava do processo de envelhecimento e a velhice, vividos pelo próprio sujeito e percebidos na vivência tanto com a geração anterior, os pais ou avós, como com os outros sujeitos da mesma idade, com os quais o entrevistado se relacionava. O segundo eixo investigava o corpo, sua representação, sua importância, a relação que o entrevistado tinha com seu próprio corpo e as mudanças vividas ao longo da vida. E o último eixo se relacionava às quedas, seus significados, seus impactos, suas consequências e sua importância na velhice.

Os critérios de inclusão foram: ter entre 65 e 75 anos, ter ou não história de queda e consentir em participar da pesquisa. Os critérios de exclusão foram ter comprometimentos mentais e físicos graves como demências, déficits neurológicos, amputações. Todos os participantes frequentavam um ambulatório de geriatria de uma autarquia hospitalar do estado de São Paulo, na cidade de São Paulo. A seleção foi feita com a ajuda dos médicos residentes, que atendiam os pacientes e os encaminhavam para a entrevista de acordo com critérios de inclusão e exclusão.

Foram entrevistados 14 idosos com idade entre 68 e 75 anos com ou sem história de quedas a partir dos 60 anos. O Quadro 1 apresenta a caracterização dos sujeitos.

Cada entrevista durou em média 30 a 40 minutos, totalizando 415 horas de gravação. As entrevistas foram gravadas com o consentimento prévio dos participantes, por meio da leitura e assinatura de Termo de Consentimento Livre e Esclarecido. Para cada entrevistado foi utilizado um nome de flor como codinome.

Quanto à análise, todas as entrevistas foram transcritas e lidas exaustivamente. Na fase pré-analítica, determinou-se a unidade de registro com palavras-chave, a unidade de contexto que contextualiza a unidade de registro, os recortes, a forma de categorização e os conceitos teóricos que pautaram o processo de análise ${ }^{17}$. A compreensão da velhice, do corpo na velhice e da queda foi feita sob a luz da representação social. Ela se dá por observações que são analisadas, por apropriação de noções e linguagens das ciências e filosofias e pela extração de conclusões. Tais representações, embora se manifestem como forma de conhecimento cognitivo através de imagens, conceitos e teorias, são socialmente produzidas e compartilhadas, formando uma realidade comum que permite a comunicação ${ }^{18}$. Toda representação é representação de algo ou alguém através de um processo no qual se dá essa relação. E o que se busca é esta relação com o mundo e com as coisas ${ }^{19}$.

\section{Resultados e discussão}

\section{Ambiguidades e ambivalências na velhice}

A velhice passa por uma construção histórica e social que resulta em múltiplos sentidos e valores. Apesar da constante ameaça de um im- 
pacto econômico negativo que o envelhecimento mundial possa causar em função das perdas consideradas inerentes a ele, fala-se também em viver mais e com mais qualidade de vida, além de descobrir-se entre os velhos um grupo consumidor privilegiado ${ }^{15}$. A velhice constrói-se, assim, de forma ambivalente, pendulando de um lado como decadência, hecatombe econômica $e$ inutilidade e, de outro, como privilégio, novas oportunidades e momento de sabedoria. Essas ambivalências e ambiguidades se refletem nos resultados do campo pesquisado.

\section{Entre o envelhecimento como processo natural e a velhice a ser combatida}

A vida aparece como um ciclo dividido em etapas e presente para todos os seres viventes, "até a árvore, um vegetal", e espera-se pelo envelhecimento como mais "uma fase normal". A comparação com o mundo dos animais e vegetais aparece como uma forma de aproximação com a natureza e assim faz do envelhecimento um processo universal, igual para todos:

Ah, envelhecimento é uma fase normal aí, natural da vida, né? Nasce, cresce e morre [ri] não é verdade? então não tem como você querer mudar. Isso foi. desde que o mundo é mundo e o ser humano existe e todos os animais até a árvore, um vegetal [...] tudo [...] tem é uma fase normal da vida (Prímula, M, 74 a.).

Debert ${ }^{20}$ aponta, do ponto de vista da antropologia, o desafio de se compreender a velhice como socialmente produzida. Segundo ela, é importante fazer a distinção entre o ciclo biológico natural, que envolve nascer, crescer e morrer, e um fato social e histórico, que diz respeito às representações que uma sociedade tem sobre a velhice de acordo com os contextos históricos, sociais e culturais.

$\mathrm{Na}$ narrativa dos entrevistados a ideia de ciclo biológico natural se expressa como uma representação constante, desconsiderando o contexto socio-histórico e as particularidades culturais que se manifestam nas sociedades contemporâneas. A queda faz parte desta perspectiva naturalizada para o indivíduo idoso, se é velho consequentemente cai.

Mas, se o envelhecimento é encarado como um processo esperado, natural e universal, ficar velho ou estar velho é uma condição da qual os entrevistados querem se afastar. A velhice é asso-

Quadro 1. Caracterização dos sujeitos.

\begin{tabular}{|l|c|l|l|l|l|l|}
\hline $\begin{array}{c}\text { Entrevistado/ } \\
\text { Sexo }\end{array}$ & Idade & $\begin{array}{c}\text { Raça/ } \\
\text { Cor }\end{array}$ & $\begin{array}{c}\text { Estado } \\
\text { civil }\end{array}$ & \multicolumn{1}{|c|}{ Escolaridade } & \multicolumn{1}{|c|}{ Profissão } & $\begin{array}{c}\text { Ocorrência de } \\
\text { Queda }\end{array}$ \\
\hline Alpínia (F) & 69 & Branca & Solteira & Superior completo & Professora aposentada & 2 quedas \\
\hline Azaleia (F) & 75 & Branca & Viúva & Superior completo & $\begin{array}{l}\text { Professora aposentada } \\
\text { (Ed. Especial) }\end{array}$ & 1 queda \\
\hline Cravo (M) & 75 & Branco & Divorciado & Superior completo & Advogado & 3 quedas \\
\hline $\begin{array}{l}\text { Crisântemo } \\
\text { (M) }\end{array}$ & 71 & Negro & Casado & $\begin{array}{l}\text { Ensino médio } \\
\text { completo }\end{array}$ & $\begin{array}{l}\text { Metalúrgico e feirante } \\
\text { aposentado }\end{array}$ & 1 queda \\
\hline Dália (F) & 72 & Branca & Casada & $\begin{array}{l}\text { Ensino médio } \\
\text { incompleto }\end{array}$ & Costureira aposentada & 1 queda \\
\hline $\begin{array}{l}\text { Flor de Lótus } \\
\text { (F) }\end{array}$ & 71 & Amarela & Viúva & Superior completo & Professora aposentada & 3 quedas \\
\hline Frésia (M) & 68 & Branco & Divorciado & $\begin{array}{l}\text { Fundamental } \\
\text { incompleto }\end{array}$ & Montador aposentado & Nenhuma queda \\
\hline Girassol (F) & 68 & Branca & Viúva & Superior completo & Professora aposentada & Nenhuma queda \\
\hline Gloxínia (F) & 68 & Negra & Viúva & Superior completo & Professora aposentada & 1 queda \\
\hline Hibisco (F) & 73 & Branca & Casada & Superior completo & Professora aposentada & Nenhuma queda \\
\hline Ixora (F) & 75 & Negra & Casada & $\begin{array}{l}\text { Ensino médio } \\
\text { completo }\end{array}$ & $\begin{array}{l}\text { Diretora de fábrica de } \\
\text { costura aposentada }\end{array}$ & Nenhuma queda \\
\hline Lírio (M) & 70 & Branco & Casado & $\begin{array}{l}\text { Ensino médio } \\
\text { completo }\end{array}$ & $\begin{array}{l}\text { Representante } \\
\text { comercial aposentado }\end{array}$ & 1 queda \\
\hline Margarida (F) & 69 & Branca & Casada & $\begin{array}{l}\text { Ensino médio } \\
\text { completo }\end{array}$ & $\begin{array}{l}\text { Funcionária pública } \\
\text { aposentada }\end{array}$ & 1 queda \\
\hline Prímula (M) & 74 & Branco & Casado & Superior completo & $\begin{array}{l}\text { Auditor de seguros } \\
\text { aposentado }\end{array}$ & 1 queda \\
\hline
\end{tabular}


ciada à doença e à incapacidade. E os velhos ou as associações com a velhice são descritas por meio de estereótipos.

As perdas aparecem quer sejam do ponto de vista físico, quer sejam relativas à disposição mental e emocional. Não importam quais sejam elas estão sempre associadas à velhice nas falas dos entrevistados. Há a comparação entre a juventude e a velhice. A primeira também aparece sob a forma de imagens estereotipadas em que tudo é possível e basta ser jovem para estar livre de riscos, inclusive do risco de cair:

Não, porque eu ainda faço tudo, não me sinto velha. Acho que velho é quando você tá numa cama, né? (Margarida, F, 69 a.).

Mas, se não é possível impedir a velhice, pode-se alongar o caminho em direção a ela. Por ser muito associada à doença e decadência, ela permite atitudes preventivas e cabe ao indivíduo deixar-se ou não ficar velho.

O processo de envelhecimento é ação do sujeito sobre si mesmo, que se deixa (permite) envelhecer. Assim, embora a velhice esteja relacionada com a incapacidade e as doenças no campo pesquisado, ela vem fortemente associada a um estado de espírito. Ficar velho é sentir-se velho, é ter uma atitude de velho caracterizada pelo pessimismo, pelo desânimo, pelo mau humor e pela inatividade. $O$ indivíduo que é velho não é capaz de definir os rumos da própria vida, sua atitude é próxima do acamado que aguarda a resolução da sua doença. Trabalhar é um sinal de que não se sente velho:

[Velhos] são pessoas que ficam deitadas, esperando que as coisas aconteçam. Eu não, eu sou uma pessoa [...] trabalho [...] eu trabalho na comunidade, eu trabalho com jovens, trabalho com pessoas, com grupo de terceira idade. Então, eu gosto de estar sempre presente no meio dos jovens. Eu trabalho com jovens como se fosse [...] não como uma pessoa idosa, mas como se fosse igual para igual com eles (Ixora, F, 75 a.).

Não pareceu haver diferenças na percepção da velhice como perda e responsabilidade individual relacionada aos marcadores sociais presentes na pesquisa.

Debert $^{11}$ aponta para uma característica da contemporaneidade em que há um embaçamento das faixas etárias e a juventude se desconecta de uma faixa específica, tornando-se um bem que oferece status a quem o possui. Junto com isso há uma mudança do discurso gerontológico. Inicialmente, tratando o velho como um incapaz que necessitava de cuidados, a gerontologia muda seu discurso a partir das pesquisas e da mídia, que apontam para uma velhice mais ativa com um grupo consumidor privilegiado.

Segundo ela, ocorre uma reprivatização do envelhecimento, processo no qual a responsabilidade por uma velhice saudável, associada a ideia de juventude, torna-se obrigação do indivíduo. A forma de se encarar a velhice como um estado de espírito, em que velho é o incapaz, o acomodado ou o doente, também traz à superfície esse processo.

Os entrevistados, ao definirem a velhice como um estado de espírito percebem uma oportunidade de não se deixarem enquadrar em um estado associado à decadência e no qual são automaticamente colocados a partir dos sessenta anos. Se velhice é estado de espírito, então basta uma atitude mais ativa e otimista para não se tornar um velho. E isso vem associado com a ideia de cada indivíduo como responsável pelo próprio envelhecimento. E esse senso de autorresponsabilidade se estende ao evento queda como um fator que impede sua ocorrência.

A ambiguidade na percepção entre um tempo privilegiado e a sensação de inutilidade aparece no campo pesquisado. A importância do mundo do trabalho para se evitar a velhice surge entre os entrevistados. A percepção de se estar envelhecendo após a aposentadoria ou mesmo o uso da atividade para afastar-se desse processo permeia as falas:

Olha, eu acho que eu comecei a perceber a mudança mesmo depois [...] já tinha até quase 60 anos eu não estava nem preocupada [...] estava indo trabalhar, voltar e tudo. Não estava pensando em nada disso, não. Depois que comecei a ficar [...] a gente fica mais em casa...porque parou de trabalhar e aí fica mais enchendo a cabeça de minhoca [...] como diz o ditado [ri] (Azaleia, F, 75 a.).

Mas o tempo livre, que a ausência de trabalho permite, também possibilita novas formas de se relacionar, quer seja consigo mesmo, quer seja nas relações familiares. Entre os homens, o tempo que não se pode dedicar aos filhos em função do trabalho, torna-se agora precioso na possibilidade da presença junto aos netos:

Na época do neto estava aposentando...comecei a reduzir todo o serviço que eu tinha, né? Trabalhava só 3 dias na semana. Aí foi onde que tive tempo de correr pra cima e pra baixo com o neto... "Ah, vou te levar... o carro está na rua mesmo!”...e assim foi....ri] (Crisântemo, M, 71 a.).

No caso das mulheres a vida profissional se mistura às obrigações familiares e domésticas, na famosa jornada dupla. Muitas vezes a aposentadoria coincide com filhos criados e que já não 
moram em casa, e com a condição de viúva. Esses fatores também favorecem um maior tempo livre. Entre as nove mulheres entrevistadas, cinco eram viúvas e oito tinham filhos.

Assim, para essas mulheres o tempo livre da aposentadoria se mistura à desobrigação também em relação ao cuidado com os filhos. Quanto aos netos, há a possibilidade de uma convivência prazerosa e cheia de afeto, mas isso ocorre justamente porque não são uma responsabilidade.

\section{Corpo de velho: entre a juventude que tudo pode e a velhice que nada pode}

Paula Sibilia ${ }^{21}$ em ensaio sobre o tratamento da imagem do velho na mídia, aponta o uso de ferramentas tecnológicas que dissimulam ou retiram rugas, flacidez e adiposidades das imagens, sobretudo quando se trata de velhos.

Segundo ela, em uma sociedade que valoriza a juventude, não só o uso de tecnologias de retoque em imagens, como a incansável e severa intervenção sobre o corpo se tornam uma obrigação, quase moral. Nesse contexto, a velhice com suas marcas corporais torna-se sinal da decadência da própria essência do ser humano e o corpo velho é algo próximo à obscenidade. $\mathrm{E}$ a queda como sinônimo de velhice torna-se expressão desta obscenidade.

As imagens refletidas no espelho a que os sujeitos dessa pesquisa se referem são construídas ${ }^{22}$. E vêm carregadas, quer seja das tonalidades afetivas individuais de um determinado momento da vida, quer seja dos discursos e práticas que envolvem a ideia de velhice na atualidade.

Entre os homens a aparência pareceu muito importante para a caracterização da velhice. E eles citam as alterações físicas que denunciam uma imagem de velho. As mulheres, embora façam menção a aparência física, parecem associar a velhice mais às sensações, em que o bem-estar simboliza não estar velho:

$E$ aí, quando a enfermeira acomodou ele na sala...eu a vi...em um determinado lugar e perguntei, a curiosidade foi tão grande... "Mas o Dr. Abelardo está bem?”, "Está! Está trabalhando...o senhor não vê que eu trouxe ele", mas ele estava corcunda (Lírio, M, 70 a.).

Além da própria imagem refletida no espelho, há também duas outras imagens apontadas nas entrevistas que são importantes para o reconhecimento da velhice: a do outro e a refletida pelo olhar do outro.

Caradec $^{23}$, em suas reflexões sobre os aspectos corporais do envelhecimento a partir da ex- periência do sujeito que envelhece, mostra que há duas estratégias usadas para o distanciamento da velhice: impedir a manifestação dos sinais corporais tidos como negativos e comparar-se favoravelmente aos outros.

Os entrevistados se utilizaram dessa estratégia ao se compararem favoravelmente aos indivíduos da mesma idade que eles e, até mesmo, aos mais jovens:

Ah...eu me sinto mais jovem... [gargalhada]... Você...já aconteceu de você encontrar pessoas que você não encontra há muito tempo...você olha $e$ fala "nossa, como envelheceu" [ri]...e você não se percebe... Não, mas eu sinto que eu sou mais jovem, incrível, né?, essa... (Flor de Lótus, F, 71 a.).

Quanto à imagem refletida pelo olhar do outro, recorre-se a Beauvoir" e sua frase "Como em nós, velho é o outro...". Segundo a autora, completando a frase anterior "...a revelação de nossa idade vem, normalmente, dos outros”. Quer seja através de afirmações explícitas sobre a velhice do próprio indivíduo, quer seja através de gestos que apontem para ela, como ceder o lugar no ônibus, Beauvoir fala desse olhar "estranho" que "metamorfoseia" o indivíduo em um velho. O olhar do observador que assiste a uma queda pode ter esta mesma função de metamorfosear o indivíduo.

Um ponto interessante sobre essa imagem que é refletida pelo olhar do outro é sua função de permitir, também, o reconhecimento da juventude, não apenas o da velhice. Entretanto, ela é provocada. Utiliza-se um estereótipo de imagem de velho para se conseguir o efeito contrário.

O corpo como um objeto passível de intervenção é uma herança do Renascimento. A partir de um mundo regido pela matemática em que os fenômenos passam a ser rigorosamente medidos e se refutam os dados sensoriais, o homem deixa de ser a única referência de orientação no espaço. "A máquina fornece a fórmula desse novo sistema ${ }^{24 "}$. Os entrevistados não fogem a essa herança. Para os homens, o corpo é uma máquina e o carro foi a metáfora predileta usada por eles.

As mulheres também encaram o corpo como objeto, mas mais próximo de um instrumento que se possa utilizar, quer seja para as relações com o mundo, quer seja para abrigar a alma:

O corpo é o nosso instrumento. É o meu instrumento para andar, para ouvir, para conversar... para me agradar...para o meu desejo e o desejo do meu parceiro, se eu tivesse...é isso aí...o corpo é isso. Tem que cuidar, muito, muito, muito bem dele. 24hs, noite e dia, tem que cuidar. Tudo que você tem é o seu corpo. Cuidar para que ele envelheça bem (Dália, F, 72 a.). 
Um ponto comum na relação de homens e mulheres com o corpo é a relação que ele mantém com a alma. Embora o corpo seja encarado quase como um objeto à parte do indivíduo, sua relação com a alma, tida como a essência do ser humano nas falas dos entrevistados, o torna uma máquina um pouco diferente:

Se você cuidou bem do corpo você cuidou bem da alma, você cuidou bem do espírito. Ou vice-versa, tem que cuidar do corpo, não adianta cuidar do espírito se o corpo não está bem...tem que estar saudável, não fazer nada de exagerado (Cravo, M, 75 a.).

As diferenças de percepção de corpo relacionadas ao gênero foram mais evidentes. $\mathrm{O}$ mesmo não se pode dizer em relação aos outros marcadores sociais presentes na pesquisa, para os quais não se observou diferenças.

O corpo tem uma representação bastante complexa. Contém uma parte biológica, um "esqueleto", mas "faz parte do ser", não é simplesmente uma coisa, um objeto. E, embora não seja objeto, tem também a função de instrumento, que pode "servir bem" ou não. Por sua vez, este servir, paradoxalmente, lhe confere uma autonomia, pois depende da sorte e quando ela não existe o corpo deixa de servir deixando seu proprietário infeliz ${ }^{24}$. E mais ainda, "o corpo é de todos", igual para todos, "e cada um é de um jeito", o que o personaliza e não o deixa ser reduzido a sua biologia. Constituído por complexas interações biológicas e fisiológicas, sensível às mudanças do ambiente e às mudanças de ordem psicológica que acometem o sujeito que o possui, máquina que serve de instrumento, mas que também é abrigo da alma, a complexidade do corpo requer cuidados em diversas esferas. Muitas vezes ele é cuidado como se cuida de uma máquina. Mas, o corpo não se reduz a isso. Há ainda uma relação com a mente ou o espírito, como já mencionado. Portanto, os cuidados não se limitam aos que se destinam somente à máquina:

...Se você tem uma vida sedentária, você vai sentir, mas se você tem uma atividade...não está preguiçoso...não está sem vontade...então você vai sentir...então você pensa em se cuidar também do corpo...Não está sentindo bem... "Ah, estou meio triste", "Mas o que você tem?", "Ah, estou assim...", então você vai cuidar. Existem ferramentas para isso...você vai cuidar de uma forma com remédios, $e$ de uma forma espiritual também (Cravo, M, 75 a.).

É importante a atividade para o corpo para não ficar "sedentário", mas a "vontade" também impulsiona esse corpo que faz "pensar" em "cuidar também" dele. E ao final os cuidados são resumidos em duas maneiras, que envolvem "remédios" e uma "forma espiritual", entrelaçando corpo e espírito. Há uma dualidade entre mente e corpo, em que este tem uma autonomia ${ }^{24}$, que necessita atividade e vigilância ou ele "se acostuma”. Mas, há também uma relação entre ambos corpo e mente, que aparece no uso da atividade de expressão corporal "para a cabeça".

A mente interfere sobre as sensações do corpo. Como na ideia de velhice, o corpo também reage a um estado de espírito, "não ficar com aquilo na cabeça" ajuda a melhorar as dores.

Relembra-se a associação entre velhice e doença presente nas primeiras preocupações sociais em relação à massa de trabalhadores envelhecidos, incapazes de produzir, do fim do século $\mathrm{XIX}^{12}$. A fala a seguir denota o entrelaçamento entre velhice, deficiência e incômodo, ainda presentes atualmente:

Porque a pessoa é velha...se a pessoa teve um problema de deficiência nas pernas...quebrou...se torna velha...ela está se tornando incômodo para você... (Cravo, M, 75 a.).

Nessa perspectiva um corpo é incapaz de ser usado através de sua locomoção, pois "as pernas" estão "quebradas", torna-se "velho" e um incômodo".

O foco dos cuidados quer seja a mente, entendida como processos cognitivos que permitem autonomia, quer seja o corpo, depende sempre da vontade do indivíduo. É de sua inteira responsabilidade cuidar-se e seu estado de espírito jovem vai ajudá-lo nisso.

\section{A queda, a velhice e a responsabilidade}

Nesse contexto, no que se refere ao indivíduo idoso a queda vem acompanhada de preocupações em função de suas consequências negativas. Entre os entrevistados, o discurso sobre o cuidado e a prevenção está presente. No entanto ele vem acompanhado com a preocupação de não haver uma identificação direta com a velhice.

A preocupação em não associar a velhice com a queda pode vir na diferenciação de suas causas. Há uma diferença entre o cair "bestamente" do cair "escorregando":

Cair nesse sentido... de escorregar... não cair bestamente... escorregando... escorregando qualquer um pode cair...você... se você estiver com sapato adequado você vai diminuir a queda (Cravo, $\mathrm{M}, 75$ a.).

Segundo esta fala, "se você estiver com sapato adequado você vai diminuir a queda". De fato, a noção do sapato adequado está ligada aos fatores 
causais extrínsecos para a queda ${ }^{6}$. Eles dependem dos comportamentos dos indivíduos, como colocar-se em situações arriscadas e usar vestuário inadequado, que podem predispor a esse evento. Ao afirmar que caiu "nesse sentido" de "escorregar", o entrevistado se aproxima desses fatores, que levam "qualquer um" a cair, segundo ele. É importante salientar que o comportamento ligado à escolha do sapato adequado envolve uma escolha autônoma do indivíduo, que está implícita no trecho citado. O entrevistado também se afasta do cair "bestamente", que traz a ideia de uma falta de controle sobre si mesmo, portanto, em oposição à ideia de controle e autonomia. Esta diz respeito à capacidade de um indivíduo tomar suas próprias decisões e mantê-la é uma meta do envelhecimento ativo ${ }^{25}$.

A queda provoca sentimentos diversos. A raiva, o susto, a vergonha dizem respeito à imagem que transparece ao outro. Estes sentimentos estiveram presentes entre os entrevistados, independente dos marcadores sociais. Cair pode significar colocar-se em uma situação de inferioridade, que pode provocar o riso de deboche ou a ajuda gerada pela preocupação em quem assiste ao ocorrido:

É o público...porque você está na rua, todo mundo está te olhando...tem gente que dá risada... Sabe que...outros já correm ali...para te socorrer...e tem outros que dão risadas, acham engraçado... (Gloxínia, F, 68 a.).

Cair não é privilégio da velhice, fato já abordado pela OMS, embora ela pontue as consequências graves de uma queda, sobretudo para crianças e velhos ${ }^{2}$. Entre os entrevistados, há consciência dessas consequências, no entanto, as reações ao evento fazem transparecer uma outra perspectiva que vai além das consequências negativas que ele gera. Em uma das quedas a gravidade do evento confrontou o entrevistado com a idade:

Não é bem assim "eu estou mudando", eu sei que com 60 anos eu virei de ponta a cabeça em uma escada e levantei vivo. Falei "Acho que estou bom ainda, né? Não é que nem o pessoal estão falando, né?", daí dessa época para cá já vai pensando, né, como vai fazer as coisas...como que vai agindo...de maneira para não... (Crisântemo, M, 71 a.).

A relação ambígua com a velhice aparece nas narrativas de queda. Ter 60 anos significa um alerta, mas sobreviver a uma queda com essa idade é sinal de que ainda "está bom”. Ela não é suficiente para considerar alguém velho "que nem o pessoal estão falando".

Nesse outro relato de queda, aparece uma ambivalência em relação à velhice:
Que eu tinha quebrado a bacia...quebrado a bacia, quebrado o joelho, a perna...pensei que eu não ia conseguir levantar. Eu fiquei assim ...rezando...e pedindo que Deus me ajudasse. Eu estava sozinha...mas aí sentei...pensei...refleti...vi que estava tudo inteiro...fui tentando e levantei...prossegui. Continuei o meu serviço normal. Mas naquele local eu nem me aproximo mais... só olho assim... (Dália, F, 72 a.).

Inicialmente, a entrevistada pensa que sofreu todas as consequências de uma queda esperadas para um indivíduo idoso, "quebrar bacia", "quebrar a perna”. Após "pensar", "refletir" e perceberse "inteira", ela "prosseguiu" com sua atividade. Mas "naquele local" não vai mais. Ter uma certa idade é um risco para ela, mas perceber-se bem a autoriza a continuar o "serviço normal". E, ao final, ela resolve o conflito entre a idade e o sentir-se bem transformando o local do evento no grande vilão, basta "não se aproximar mais".

Esta outra entrevistada revela também uma relação diversa com a queda. Cair gera benefício, o mesmo ligado à ideia da velhice, poder escolher entre tarefas agradáveis e desagradáveis:

Então, para pegar coisas lá de cima... eh...me faço assim...eu tenho quase certeza que eu vou conseguir subir cuidadosamente, pegar... e tal...mas... eu me faço assim...estou me dando o direito de falar... não quero mais dirigir, eu tenho certeza que posso dirigir ainda...mas eu falo "Ah, não quero mais, né?”, me faço de...já...já...não quero fazer determinadas coisas (Flor de Lótus, F, 71a.).

Pelo fato de já ter sofrido algumas quedas, ela evita subir em bancos e escadas, apesar de "ter quase certeza de que vai conseguir". Mas o que seria um impedimento a sua independência, permite a ela "se dar o direito de falar": "não quero fazer determinadas coisas".

Um outro sentimento que acompanha a queda é a recriminação por ter caído. E é o que acontece com este entrevistado, cair deixou-o "chateado", fazendo com que ele se sentisse "imprudente", lembrando-se que pelo dicionário Houaiss $^{26}$ o imprudente é "quem é descuidado". (p.1586):

...Não...veio que foi uma imprudência, né, e depois deixa a gente chateado, né? (Lírio, M, 70 a.).

E é o descuidado que se deixa ficar velho, de acordo com os entrevistados. Esta percepção da velhice foi comum a todos os entrevistados, independente dos marcadores sociais presentes nesta pesquisa.

Para esta entrevistada, apenas uma pessoa "louca" é que "fica caindo por nada". E nada a exime da responsabilidade de ter caído. A ima- 
gem de uma "louca", que é responsável por suas próprias quedas que não têm qualquer motivo aparente, a deixa "brava":

Eu fiquei brava por ter caído, "louca, fica caindo do nada”. Foi isso (Alpínia, F, 69 a.).

A responsabilidade pela imagem que passa ao outro é do próprio sujeito. Cair passa a imagem do doente, do irresponsável, do frágil e da louca, tudo isso alinhavado com o fato de já se ter mais de 60 anos, ser um velho. Mas o "velho é trapo" (Ixora, F, 75a.) que não tomou as medidas necessárias para impedir a velhice.

\section{Considerações finais}

A velhice tem sido comumente caracterizada como um momento de doenças e incapacidades. Os entrevistados, a partir dessa perspectiva, logo fazem uma associação às atitudes das pessoas e que podem caracterizá-las como velhas independente da sua idade cronológica. E a ponte entre o biológico e um sentimento é feita, passa-se a "sentir-se" velho, diferente do "ser" velho uma condição passageira, portanto passível de ser mudada.

Há também a ideia do velho como aquele que chegou ao fim da vida, portanto está mais perto da morte. Distanciar-se da velhice é distanciar-se da morte.

Mas a velhice também pode se tornar um tempo privilegiado. Para os homens, um tempo de aproximação com seus netos, como forma de compensar a ausência em relação aos próprios filhos, imposta pelo trabalho. Para as mulheres, uma desobrigação com respeito aos cuidados com a casa e com os filhos, que permite um tempo para si mesmas. A velhice, dessa forma, passa a ser vivida de forma ambivalente.

As categorias que emergiram no estudo quanto à velhice denotaram uma ambiguidade em sua vivência. Segundo os entrevistados, esta fase é um ciclo natural e um destino comum a todos os seres humanos, mas também significa doença e incapacidade, portanto, há o desejo e o esforço de afastar-se dela. Há também a ideia de velhice como um sentimento, o que facilita a aproximação ou afastamento dela. Isto, por sua vez, a torna uma responsabilidade individual, reforçando o processo de reprivatização ${ }^{15}$ do envelhecimento. A aposentadoria mostrou-se como um momento de determinação do início da velhice, mas também se apresentou como ideal à ressig- nificação das relações, uma chance para rever os papéis, atualizá-los ou mesmo estabelecer outras relações, quer consigo mesmo, quer com outras pessoas. Quanto à ideia da experiência atrelada à velhice, isto mostrou uma ambivalência entre adquirir a sabedoria e chegar ao fim da jornada, onde nada mais pode ser descoberto. O corpo apresentou-se através de um trabalho sobre duas imagens que se contrapõem: a do velho, cuja decadência o aproxima da morte e a do jovem, que tem características quase sobre-humanas.

O corpo foi descrito em sua dualidade com a mente em uma relação de reciprocidade. A função primordial de ambos é a proteção de uma alma, que se supõe existir, herança do Cristianismo. Esta é tida como essência do ser humano, devendo ser preservada.

Embora o combate às marcas corporais da velhice tome formas diferentes entre homens e mulheres entrevistados, ambos acabam investindo em uma imagem que se deseja passar e que está mais ligada às atitudes do que à aparência.

Cuidar do corpo é cuidar da alma e cuidar da alma é cuidar do corpo. $\mathrm{O}$ evento queda tem lugar nesse corpo na velhice, vivido como expressão de uma essência que se deseja e se projeta como jovem, ou ao menos, distante de uma representação de velhice como decrepitude.

A caracterização desse evento com todas as suas consequências gera uma pressão sobre o velho, pois cair envolve toda uma gama de resultados graves que vão além do indivíduo. Junte-se a isso, a representação de uma velhice passível de ser tratada ou adiada. Não cair, mais do que um cuidado, torna-se uma obrigação do velho.

De acordo com a perspectiva de uma velhice percebida quase como uma falha do indivíduo em um corpo que expressa a sua essência, cair torna-se a ameaça de exposição dessa falha.

A vivência de corpo não parece interferir diretamente sobre o risco para a queda. No entanto, sua compreensão, bem como a representação da queda no corpo do velho, fornece subsídios para uma abordagem preventiva em relação a esse evento.

Apesar dos resultados trazerem avanços na literatura existente, o presente estudo apresenta algumas limitações. A principal a ser observada é a dificuldade de generalização dos resultados. Ademais, a pesquisa contou com menor número de participantes do sexo masculino, reduzindo a heterogeneidade do grupo investigado. 


\section{Colaboradores}

ATC Estrêla contribuiu com o desenho e redação do artigo, a construção e análise dos dados. $\mathrm{R}$ Machin contribuiu com o desenho do artigo, análise dos dados e elaboração do texto final.

\section{Referências}

1. Organização Mundial da Saúde (OMS). Relatório Global da OMS sobre prevenção de quedas na velhice. São Paulo: Secretaria de Estado da Saúde; 2010.

2. World Health Organization (WHO). Falls, media centre, fact sheet $n^{\circ}$ 344, August 2010. Genebra: WHO; 2010.

3. Perracini MR, Ramos LR. Fatores associados a quedas em uma coorte de idosos residentes na comunidade. Rev Saude Publica 2002; 36(6):709-716.

4. Couto FB, Perracini MR. Análise multifatorial do perfil de idosos ativos com história de quedas. Rev Bras Geriatr Gerontol 2012; 15(4):693-706.

5. Tinetti ME, Kumar C. The patient who falls: "It's always a trade-off". JAMA 2010; 303(3):258-266.

6. SRM, Buksman S, Perracini M, Py L, Barreto KML, Leite VMM. Quedas em idosos. Projeto Diretrizes. Associação Médica Brasileira e Conselho Federal de Medicina. Rev AMRIGS 2004; 48(1):43-65.

7. Nyman SR, Ballinger C, Phillips JE, Newton R. Characteristics of outdoor falls among older people: a qualitative study. BMC Geriatrics 2013; 13(125):1-14.

8. Gasparotto LPR e Santos JFFQ. A importância da análise dos gêneros para fisioterapeutas: enfoque nas quedas entre idosos. Fisioter Movime PUC-PR 2012; 25(4):701-707.

9. Beauvoir S. A velhice. São Paulo: Difusão Europeia do Livro; 1970.

10. GG. A dissolução da vida adulta e a juventude como valor. Horiz Antropol 2010; 34:49-70.

11. Debert GG. Velhice e o curso da vida pós-moderno. Rev USP 1999; 42:70-83.

12. Silva LRF. Da velhice à terceira idade: o percurso histórico das identidades atreladas ao processo do envelhecimento. Hist Cien Saude 2008; 15(1):155-168.

13. Laslett P. A fresh map of life: the emergence of third age. Cambridge: Harvard University Press; 1991.

14. Lenoir R. L'invention du "troisième age". Actes de la Recherche em sciences sociales 1979; 26-27:57-82.

15. Debert GG. A reinvenção da velhice. São Paulo: Edusp; 2004.

16. Flick U. Uma introdução à pesquisa qualitativa. $2^{\mathrm{a}}$ ed. Porto Alegre: Bookman; 2004.

17. Minayo MCS. Análise qualitativa: teoria, passos e fidedignidade. Cien Saude Colet 2012; 17(3):621-626.
18. Moscovici S. La representación social: um concepto perdido. In: El psicoanálisis, su imagen y su publico. 2a ed. Buenos Aires: Editora Huemul; 1979. p. 27-44.

19. Jodelet D. La representación social: fenómenos, concepto y teoria. In: Moscovici S, organizador. Psicologia Social. Barcelona: Paídos; 1985. p. 469-494.

20. Debert GG. A antropologia e o estudo dos grupos e das categorias de idade. In Barros MML, organizadora. Velhice ou terceira idade? $3^{\text {a }}$ ed. Rio de Janeiro: FGV Editora; 2003. p. 49-67.

21. Sibilia P. A moral da pele lisa e a censura midiática da velhice: o corpo velho como uma imagem com falhas. In Goldenberg M, organizadora. Corpo, envelhecimento e felicidade. $2^{\text {a }}$ ed. Rio de Janeiro: civilização brasileira; 2014. p. 83-108.

22. Featherstone M, Wernick A. Introduction. In Featherstone M, Wernick. A Images of aging: cultural representations of later life. Taylor \& Francis e-library; 2005.

23. Caradec V. Sexagenários e octogenários diante do envelhecimento do corpo. In Goldenberg $\mathrm{M}$, organização. Corpo, envelhecimento e felicidade. $2^{\text {a }}$ ed. Rio de Janeiro: civilização brasileira; 2014. p. 21-44.

24. Le Breton D. Antropologia do corpo e modernidade. 3aed. Petrópolis: Editora vozes; 2013.

25. World Health Organization (WHO). Envelhecimento ativo: uma política de saúde. Brasília: OPAS; 2005.

26. Houaiss A, Vilar MS. Dicionário Houaiss da Língua Portuguesa. Rio de Janeiro: Objetiva; 2001.

Artigo apresentado em 18/09/2019

Aprovado em 01/09/2020

Versão final apresentada em 03/09/2020

Editores-chefes: Romeu Gomes, Antônio Augusto Moura da Silva 